\title{
Study of Complex Formation Constants for Some Cations With O-Phenylenediamine in Binary Systems Using Square Wave Polarography Technique
}

\author{
Azizollah Nezhadali*, Hanieh Sharifi \\ Department.of Chemistry, Payame Noor University, Mashhad, Iran \\ E-mail:aziz_nezhadali@yahoo.com \\ Received January 25, 2010; revised March 10, 2010; accepted November 4, 2010
}

\begin{abstract}
The formation of metal cation complexes between o-phenylenediamine with metal ions, $\mathrm{Ni}^{2+}, \mathrm{Cu}^{2+}, \mathrm{Zn}^{2+}$, $\mathrm{Pb}^{2+}$ and $\mathrm{Cr}^{3+}$ were studied in the dimethylformamide/water $\left(\mathrm{DMF} / \mathrm{H}_{2} \mathrm{O}\right)$, acetonitrile/water $\left(\mathrm{AN} / \mathrm{H}_{2} \mathrm{O}\right)$ and ethanol/water $\left(\mathrm{EtOH} / \mathrm{H}_{2} \mathrm{O}\right)$ binary systems using square wave polarography (SWP) technique. The stoichiometry and stability of the complexes were determined by monitoring the shifts in half-waves or peak potentials of the polarographic waves of metal ions against the ligand concentration. In the most cases, the formation constants of complexes decreased with increasing amounts of $\mathrm{H}_{2} \mathrm{O}$, DMF and EtOH in $\mathrm{AN} / \mathrm{H}_{2} \mathrm{O}$, $\mathrm{DMF} / \mathrm{H}_{2} \mathrm{O}$ and $\mathrm{EtOH} / \mathrm{H}_{2} \mathrm{O}$ binary systems, respectively. The stoichiometry of the complexes was found 1:1. The results obtained show that there is an inverse relationship between the formation constant of the complexes and the donor number of the solvents based on the Gatmann donocity scale. Also, the stability constants show a high sensitivity to the composition of the mixed solvent systems. In most of the systems investigated, $\mathrm{Cr}^{3+}$ cation forms a more stable complex with o-phenylenediamine than other four cations and the order of selectivity of this ligand for cations in pure water is: $\mathrm{Cr}^{3+}>>\mathrm{Cu}^{2+}>\mathrm{Ni}^{2+}>\mathrm{Zn}^{2+}>\mathrm{Pb}^{2+}$.
\end{abstract}

Keywords: Complex Formation Constant, SWP, Stoichiometry, Cations, Binary System

\section{Introduction}

Polarographic investigations of chemical substances are not restricted to the measurements in aqueous solution. Some inorganic polarography in non-aqueous solvents has received increasing attention. Polarographic study of metal ions viz. cobalt, lithium, lead, cadmium etc. in various organic solvents have been carried out by many research groups $[1,2]$.

The study of the metal complexes in non-aqueous solvents by polarographic methods has attracted much attention by researchers. Nature of the solvent has a considerable influence on the composition and stability of complexes formed (Turyan and Chebotar, 1959). Lane and co-workers (Lane, 1960) made a polarographic study of the complexes of lead, cadmium and copper with thiourea and its alkyl derivatives. Turyan and his collaborators studied halides and thiocyanate complexes of lead and cadmium ion in various solvents and observed a linear relationship between values of $\mathrm{pK}$ for the complex and the inverse of the dielectric constants. Polarographic studies of complexes in methanol and ethanol by Migal et al. and others have shown that there is a sharp increase in the stability of complexes above $20 \%$ concentration which they attributed to the salvation effect. Polarographic investigations of lead, cadmium and zinc in dimethylformamide are done by many workers (Fujinaga and Puri, 1974; Sharma et al., 1975; Sharma et al., 1975). Different workers in this field have obtained different results. Thus it is a need for systematic study of the influence of aqueous organic solvent mixtures on complex formation [3]. For the purpose we investigated some cations with o-phenylenediamine complexes in aqueous mixtures of dimethylformamide (DMF), acetonitrile (AN) and ethanol (EtOH). The goal of many studies involving complex formation in mixed solvent systems has been to investigate the effect of solvent composition on the stability and nature of the complex formed [4]. There is well known that the selectivity of the complexation is normally strongly dependent on the solvating ability of the solvent with respect to the cation and the ligand [5-7]. 
As a result, variations in the nature of the solvent produce significant changes in the binding properties of the ligand [8]. Various physiochemical methods have been used to obtain the stability constants of complexes [9-10]. Of the various techniques polarography has proved to be a useful means for investigation of both the stoichiometry and stability of complexes. Due to the higher speed, higher resolution and also low consumption of mercury in SWP, we preferred to use this technique for the present investigation. In the present work we investigated the effects of the solvent properties on the selectivity and stability of complexes of o-phenylenediamine with $\mathrm{Zn}^{2+}, \mathrm{Ni}^{2+}, \mathrm{Cu}^{2+}, \mathrm{Pb}^{2+}$ and $\mathrm{Cr}^{3+}$ metal cations in $\mathrm{DMF} / \mathrm{H}_{2} \mathrm{O}, \mathrm{EtOH} / \mathrm{H}_{2} \mathrm{O}$ and $\mathrm{AN} / \mathrm{H}_{2} \mathrm{O}$ binary systems using the square wave polarographic technique.

\section{Experimental Section}

\subsection{Reagents and Solvent}

Reagent grade o-phenylenediamine (o-PDA), potassium nitrate $\left(\mathrm{KNO}_{3}\right)$, zinc(II)nitrate, copper(II)nitrate, lead (II)nitrate, nickel(II)nitrate, chromium(III)nitrate (all from Merck) and mercury were used without further purification. The organic solvents, dimethylformamide, ethanol and acetonitrile (all from Merck) and also distilled water with the highest purity, were used for the preparation of the desired mixed solvents. The nitrogen gas was purchased from Sabalan Co, Tehran, Iran.

\subsection{Apparatus}

The polarographic measurements, were carried out on a 797 VA Computrace Polarographic Analyzer (Metrohm) with a hanging mercury drop electrode (HMDE) in a three electrode arrangement. $\mathrm{An} \mathrm{Ag} / \mathrm{AgCl}$ electrode with a bridge containing the base electrolyte as the electrolyzed solution was employed. The auxiliary electrode was a Pt wire. A solution of $0.025 \mathrm{M}$ potassium nitrate was used as the base electrolyte. The distilled water apparatus was local made set.

The instrumental parameters were voltage step, $5 \mathrm{mV}$; pulse amplitude, $20 \mathrm{mV}$; equilibration time, $5 \mathrm{~s}$; sweep rate, $251.8 \mathrm{mV} / \mathrm{s}$; frequency, $50 \mathrm{~Hz}$ for the SWP technique.

\subsection{Procedure}

A solution $0.025 \mathrm{M}$ of supporting electrolyte $\left(\mathrm{KNO}_{3}\right)$ and $0.1 \mathrm{mM}$ of metal salt in a polarographic cell was de-aerated by a stream of nitrogen gas $(99.999 \%)$ for 5.0 min; and the half-wave potential of the solution was measured, then the addition of ligand was performed in separate steps to form the desirable concentration of the ligand in the solution .

\section{Results and Discussion}

In polarographic investigations, the significant quantity for studying the formation constant of metal ion complexes is the half-wave potential $\left(\mathrm{E}_{1 / 2}\right)$ or the differential pulse peak potential $\left(\mathrm{E}_{\mathrm{p}}\right)$ of the complex and the free metal ion. The difference in $\mathrm{E}_{1 / 2}$ or $\mathrm{E}_{\mathrm{p}}$ between the complex and the metal ion is used in the calculation of the stability constant of the complexes [11-14]. The reaction between o-PDA with $\mathrm{Zn}^{2+}, \mathrm{Ni}^{2+}, \mathrm{Cu}^{2+}, \mathrm{Pb}^{2+}$ and $\mathrm{Cr}^{3+}$ was studied in $\mathrm{DMF} / \mathrm{H}_{2} \mathrm{O}, \mathrm{EtOH} / \mathrm{H}_{2} \mathrm{O}$ and $\mathrm{AN} / \mathrm{H}_{2} \mathrm{O}$ binary mixtures of various compositions. We used $\mathrm{H}_{2} \mathrm{O}$ as the solvating solvent for the ligand. In general, the addition of ligand to $\mathrm{Zn}^{2+}, \mathrm{Ni}^{2+}, \mathrm{Cu}^{2+}, \mathrm{Pb}^{2+}$ and $\mathrm{Cr}^{3+}$ solutions in $0.025 \mathrm{M} \mathrm{KNO}_{3}$ shifts the reduction potential $\left(\mathrm{E}_{\mathrm{p}}\right)$ of the metal ions toward more negative values. As an example, the square wave polarograms of $\mathrm{Zn}^{2+}$ ion in the presence of different concentrations of o-phenylenediamine in one of the DMF/ $\mathrm{H}_{2} \mathrm{O}$ binary systems is shown in Figure 1.

Lingane [13] derived the following relationship between concentrations of ligand $(L)$ and shift in half-wave potential to calculate the formation constants of the cation and ligand :

$$
\Delta E_{1 / 2}=\left(E_{1 / 2}\right)_{C}-\left(E_{1 / 2}\right)_{M}=-(R T / n F)\left(\ln K_{f}+p \ln [L]_{t}\right)(1)
$$

where $\left(E_{1 / 2}\right)_{M}$ and $\left(E_{1 / 2}\right)_{C}$ are the half-wave potentials of free and complexed metal ion, respectively, $n$ is the number of electrons transferred for reduction, $[L]_{t}$ is the analytical concentration of the ligand, $K_{f}$ is the complex formation constant and $\mathrm{m}$ is the molar ratio of complexing agent to cation. Different experimental techniques such as potentiometric, voltammetric [14], or spectrophotometric [10] techniques are reported in the scientific literature for the measurements of $K_{f}$. In this study, the shift of the half-wave potential is measured as mentioned in electrochemistry textbooks. Effect of complexing agent on polarographic half wave potentials at the dropping mercury electrode is applicable whenever the electron transfer is reversible.

The value of $K_{f}$ and $\mathrm{p}$ can be obtained from the intercept and slope of the linear plots of $\Delta E_{1 / 2} /(R T / n F)$ vs log $[L]_{t}$, respectively. In most of the binary mixed solvent systems used in this investigation, addition of the o-PDA ligand to the cation solutions in the presence of $\mathrm{KNO}_{3}$ shifts the reduction potential of the metal ions towards a more negative value (Figure 1).

In Figure 1 the difference between the half-wave potentials of the free and complexed metal ion is a measure of the complex stability. The more stable the complex between the ligand and a cation the more negative shift of potential is needed for reduction at the surface of the electrode. In the all cases, the cyclic voltametric result 


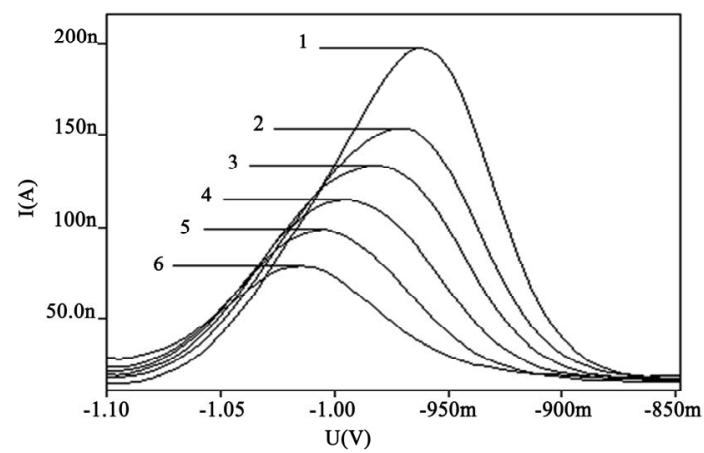

Figure 1. The square wave polarograms of $0.1 \mathrm{mM} \mathrm{Zn}^{2+}$ ion in a $\mathrm{DMF} / \mathrm{H}_{2} \mathrm{O}\left(60 \% \mathrm{DMF}+40 \% \mathrm{H}_{2} \mathrm{O}\right)$ binary system with different concentration of o-PDA ligand: (1) 0 , (2) 0.19 , (3) 0.25 , (4) 0.3 , (5) 0.35 and (6) $0.39 \mathrm{mM}$.

show that the reductions of $\mathrm{Zn}^{2+}, \mathrm{Ni}^{2+}, \mathrm{Cu}^{2+}, \mathrm{Pb}^{2+}$ and $\mathrm{Cr}^{3+}$ in the presence of the ligand are reversible. The cyclic voltamogram $(\mathrm{CV})$ of the $\mathrm{Zn}^{2+}$ cation ion in the presence of o-PDA in DMF $/ \mathrm{H}_{2} \mathrm{O}, \mathrm{EtOH} / \mathrm{H}_{2} \mathrm{O}$ and $\mathrm{AN} / \mathrm{H}_{2} \mathrm{O}$ binary systems is shown in Figure 2. The peak potentials in Figure 2 shows a reversible polarogram for this study. The Similar polarograms were obtained for the other systems (not shown).

As an example, the variations in $\Delta E_{1 / 2} /(R T / n F)$ as a function of $\log$ [o-PDA $]_{\mathrm{t}}$ for the complex formation between o-PDA and $\mathrm{Cu}^{2+}$ ion in $\mathrm{DMF} / \mathrm{H}_{2} \mathrm{O}$ binary systems is shown in Figure 3.

The slope of the linear plots in Figure 3 gave a value of $\mathrm{m}=1$, in agreement with the formation of a 1:1 complex between $\mathrm{Zn}^{2+}$ ion and o-PDA in the solution the similar behaviors were observed for the other systems. The formation constants of complexes were obtained by fitting the polarographic data to Equation (1).

From Table 1, it is seen that the stability of the complexes of these metal ions with o-PDA decreases in the order of $\mathrm{Cr}^{3+}>>\mathrm{Cu}^{2+}>\mathrm{Ni}^{2+}>\mathrm{Zn}^{2+}>\mathrm{Pb}^{2+}$ in pure water system used in this study.

The stability of a complex formed in a solution

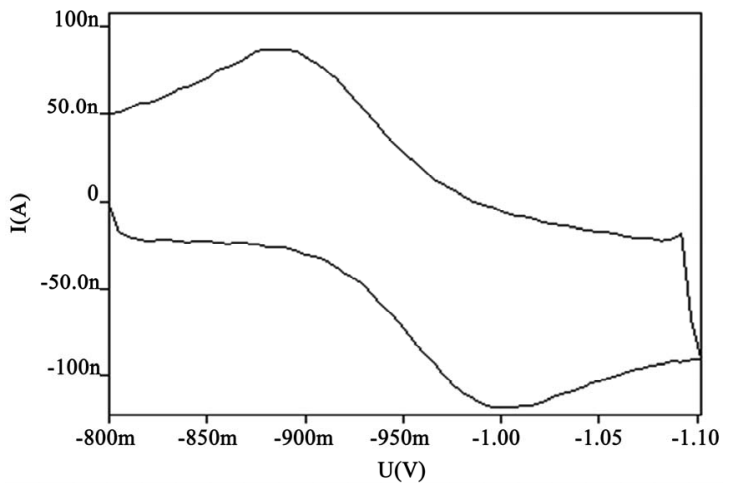

Figure 2. The cyclic voltamogram of the $\mathrm{Zn}^{2+}$ in the presence of o-PDA in a DMF- $\mathrm{H}_{2} \mathrm{O}$ binary system.

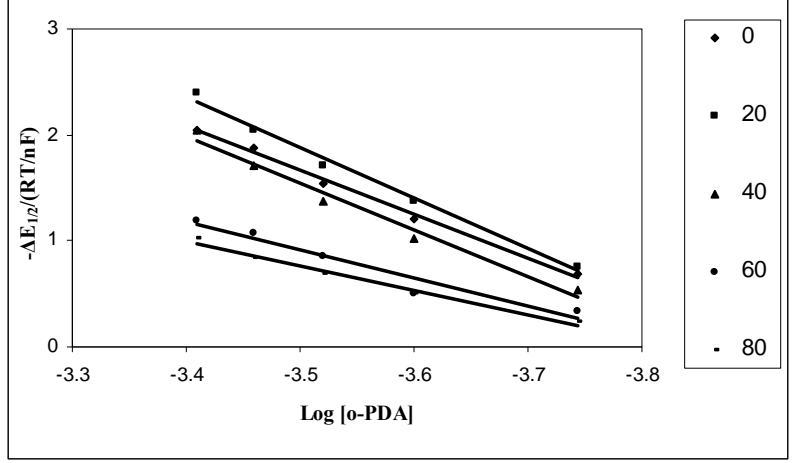

Figure 3. The linear plots of $\mathrm{E}_{1 / 2} /(\mathrm{RT} / \mathrm{nF})$ vs. $\log [0-\mathrm{PDA}]_{\mathrm{t}}$ for the $\mathrm{Cu}^{2+}-0$-PDA complex in different $\mathrm{DMF} / \mathrm{H}_{2} \mathrm{O}$ binary mixtures. The curves show: (४) $0,(\square) 20,(\Delta) 40,(\bullet) 60$ and (-) $80 \%(v / v)$ of the solvents.

strongly depends on the nature of the solvent medium. During the complexation step, the ligand should be able to replace the solvent molecules as completely as possible in the first salvation shell of cation, or the cation should be able to replace the solvent molecule with the ligand [15]. Therefore, the variation of the solvent produces a significant change in the binding properties and selectivity of the ligand for a certain cation over the others. As is evident from Table 1, in the most cases there is an inverse relationship between the formation constant of the complexes and the donor number of solvents based on a Gattmann donocity scale. The variation of the formation constants of the o-PDA complexes with $\mathrm{Zn}^{2+}$, $\mathrm{Ni}^{2+}, \mathrm{Cu}^{2+}, \mathrm{Pb}^{2+}$ and $\mathrm{Cr}^{3+}$ cations as a function of solvent composition in a $\mathrm{AN} / \mathrm{H}_{2} \mathrm{O}$ binary systems is shown in Figure 4.

As is evident from Table 1, in general the stability of all complexes decreases with an increasing concentration of DMF in a DMF/ $\mathrm{H}_{2} \mathrm{O}$ and $\mathrm{H}_{2} \mathrm{O}$ in a $\mathrm{AN} / \mathrm{H}_{2} \mathrm{O}$ binary systems. Also in the most complexes formation constants decreases with an increasing concentration of $\mathrm{EtOH}$ in a EtOH/ $\mathrm{H}_{2} \mathrm{O}$ binary system (Table 1). The solvating ability

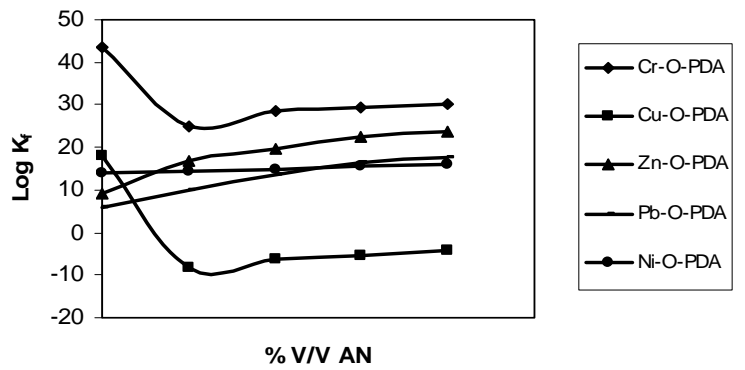

Figure 4. The variation of stability constants of different metal ion complexes of o-PDA in $\mathrm{AN} / \mathrm{H}_{2} \mathrm{O}$ binary systems. The curves show: ( $\diamond) \mathrm{Cr}^{3+}-\mathrm{o}-\mathrm{PDA}$; (a) $\mathrm{Cu}^{2+}-\mathrm{o}-\mathrm{PDA}$; (A) $\mathrm{Zn}^{2+}-0-P D A ;(-) \mathrm{Pb}^{2+}-\mathrm{o}-\mathrm{PDA}$ and $(\bullet) \mathrm{Ni}^{2+}-0-\mathrm{PDA}$, complexes. 
Table 1. The $\log \mathrm{K}_{\mathrm{f}}$ Values of $\mathrm{Zn}^{2+}, \mathrm{Ni}^{2+}, \mathrm{Cu}^{2+}, \mathrm{Pb}^{2+}$ and $\mathrm{Cr}^{3+}$ complexes with o-PDA in the binary solvent mixtures.

\begin{tabular}{|c|c|c|c|c|c|c|}
\hline Medium & $\begin{array}{c}\text { Solvent } \\
\text { Composition }\end{array}$ & & & $\operatorname{LogK}_{\mathrm{f}} \pm \mathrm{RSD}^{\mathrm{a}}$ & & \\
\hline \multirow{6}{*}{$\mathrm{EtOH} / \mathrm{H}_{2} \mathrm{O}$} & $\mathrm{V} / \mathrm{VH}_{2} \mathrm{O} \%$ & $\mathrm{Ni}^{2+}$ & $\mathrm{Cr}^{3+}$ & $\mathrm{Zn}^{2+}$ & $\mathrm{Cu}^{2+}$ & $\mathrm{Pb}^{2+}$ \\
\hline & 100 & $13.9 \pm 0.02$ & $43.50 \pm 0.03$ & $9.00 \pm 0.03$ & $17.98 \pm 0.07$ & $6.00 \pm 0.01$ \\
\hline & 80 & $12.70 \pm 0.01$ & $35.70 \pm 0.02$ & $12.00 \pm 0.04$ & $21.80 \pm 0.06$ & $7.10 \pm 0.07$ \\
\hline & 60 & $8.27 \pm 0.02$ & $11.00 \pm 0.03$ & $10.91 \pm 0.02$ & $21.00 \pm 0.05$ & $7.10 \pm 0.03$ \\
\hline & 40 & $6.20 \pm 0.03$ & $4.30 \pm 0.05$ & $10.40 \pm 0.80$ & $20.70 \pm 0.03$ & $9.25 \pm 0.03$ \\
\hline & 20 & $7.60 \pm 0.07$ & $-21.27 \pm 0.02$ & $3.22 \pm 0.05$ & $20.20 \pm 0.00$ & $13.90 \pm 0.04$ \\
\hline \multirow[t]{5}{*}{$\mathrm{AN} / \mathrm{H}_{2} \mathrm{O}$} & 100 & $13.90 \pm 0.02$ & $43.50 \pm 0.03$ & $9.00 \pm 0.03$ & $17.98 \pm 0.07$ & $6.00 \pm 0.01$ \\
\hline & 80 & $14.50 \pm 0.02$ & $24.78 \pm 0.04$ & $17.00 \pm 0.02$ & $-8.17 \pm 0.02$ & $9.80 \pm 0.02$ \\
\hline & 60 & $14.96 \pm 0.01$ & $28.41 \pm 0.02$ & $19.70 \pm 0.05$ & $-6.07 \pm 0.02$ & $13.39 \pm 0.01$ \\
\hline & 40 & $15.51 \pm 0.03$ & $29.24 \pm 0.09$ & $22.40 \pm 0.04$ & $-5.45 \pm 0.02$ & $16.40 \pm 0.02$ \\
\hline & 20 & $16.80 \pm 0.02$ & $30.24 \pm 0.06$ & $23.50 \pm 0.03$ & $4.15 \pm 0.02$ & $17.50 \pm 0.02$ \\
\hline \multirow[t]{5}{*}{$\mathrm{DMF} / \mathrm{H}_{2} \mathrm{O}$} & 100 & $13.9 \pm 0.02$ & $43.50 \pm 0.03$ & $9.00 \pm 0.03$ & $17.98 \pm 0.07$ & $6.00 \pm 0.01$ \\
\hline & 80 & $6.30 \pm 0.03$ & $24.40 \pm 0.03$ & $9.40 \pm 0.01$ & $20.93 \pm 0.05$ & $0.00 \pm 0.00$ \\
\hline & 60 & $-7.02 \pm 0.08$ & $17.00 \pm 0.05$ & $20.00 \pm 0.02$ & $18.20 \pm 0.01$ & $-4.90 \pm 0.05$ \\
\hline & 40 & $-4.45 \pm 0.05$ & $12.00 \pm 0.02$ & $17.49 \pm 0.04$ & $11.00 \pm 0.02$ & $-17.44 \pm 0.02$ \\
\hline & 20 & $-26.00 \pm 0.04$ & $4.80 \pm 0.1$ & $7.30 \pm 0.1$ & $8.20 \pm 0.03$ & $-24.00 \pm 0.05$ \\
\hline
\end{tabular}

${ }^{a}$ Relative standard derivation $(\mathrm{n}=3)$

of the solvent, as expressed by the Guttmann donocity scale, plays a fundamental role in the complexation reactions [14]. The donor number is nearly a molecular property of the solvent, which is easily determined by experiment. It expresses the total amount of interaction with an acceptor molecule, including contribution both by dipole-dipole or dipole-ion interactions and by the binding effect caused by the availability of the free electron pair; to some extent steric properties of the solvent molecules may be contained in it. Thus the donor number is considered a semi quantitative measure of solute solvent interactions. It is recognized that no allowance has been made for specific interactions between certain individual donor-accepter species. Such refinements are currently impossible owing to a lack of knowledge, and indeed of experimental data, as to the precise nature of such specific interactions. In a weak solvating solvent such as AN, which has a low Guttmann donocity ( $\mathrm{DN}=$ 14), the salvation of the metal cations and possibly of the ligand should be weaker than in solvents with a strong solvating ability such as for DMF $(\mathrm{DN}=26.6), \mathrm{EtOH}$ ( $D N=19)$ and $\mathrm{H}_{2} \mathrm{O}(\mathrm{DN}=18)$. Therefore, less energy is necessary for the desolvation step of the $\mathrm{Zn}^{2+}, \mathrm{Ni}^{2+}, \mathrm{Cu}^{2+}$, $\mathrm{Pb}^{2+}$ and $\mathrm{Cr}^{3+}$ cations and probably of the ligand during the complex formation in the case of AN than in $\mathrm{H}_{2} \mathrm{O}$. Also, the low formation constants can be explained by hydrogen bonding between water and the ligand in the organic/water binary mixtures, where the ligand is not free to form the complex with the cations.

It is interesting to note that a non-linear behavior is observed for variation of the stability constant $\left(\log \mathrm{K}_{\mathrm{f}}\right)$ of complexes versus the composition of $\mathrm{AN} / \mathrm{H}_{2} \mathrm{O}$ binary systems. As it is evident from Figure 4, when the con- centration of AN increases, the stability constants of complexes first decrease suddenly, and then increase gradually after about $20 \%$ of AN. This behavior may by due to some kind of solvent-solvent interactions between these protic and aprotic solvents when they are mixed with one another or it may by due to preferential salvation of the cations in these binary systems. In some cases, as seen from Table 1 the value of $\mathrm{K}_{\mathrm{f}}$ decreases and irreversibility increases in acetonitrile in comparison to water. Since the value of dielectric constant of solvent is very low and again viscosity also decreases regularly, the shifts of $E_{1 / 2}$ to more positive values and the change of $i_{d}$ can be best explained on the basis of salvation and viscosity [15-17].

\section{Conclusions}

The results obtained show that there is an inverse relationship between the formation constant of the complexes and the donor number of the solvents based on the Gatmann donocity scale. The results show that, 1 the stability of all complexes decreases with an increasing concentration of DMF in $D M F / \mathrm{H}_{2} \mathrm{O}$, water in $\mathrm{AN} / \mathrm{H}_{2} \mathrm{O}$ and $\mathrm{EtOH}$ in $\mathrm{EtOH} / \mathrm{H}_{2} \mathrm{O}$ binary systems. The stoichiometry of the complexes was found $1: 1$. As it is seen from the results, in the mixed solvent systems used in this study, the stability of complexes of the metal cations with o-phenylenediamine decreases in the order of $\mathrm{Cr}^{3+}>>$ $\mathrm{Cu}^{2+}>\mathrm{Ni}^{2+}>\mathrm{Zn}^{2+}>\mathrm{Pb}^{2+}$. Also, a non-linear behavior is observed for variation of the stability constant $\left(\log \mathrm{K}_{\mathrm{f}}\right)$ of some complexes versus the composition of $\mathrm{AN} / \mathrm{H}_{2} \mathrm{O}$ binary systems. This behavior may by due to some kind of solvent-solvent interactions between these protic and 
aprotic solvents when they are mixed with one another or it may by due to preferential salvation of the cations in these binary systems

\section{Acknowledgements}

The authors gratefully acknowledge the financial support of this research by the Research Council of Payame Noor University (PNU).

\section{References}

[1] P. Arthur and H. Lyons, "Use of Asymmetrically Polarized Dropping-Mercury Electrodes in ControlledPotential Polarography," Analytical Chemistry, Vol. 24, No. 4, 1952, pp. 1422-1428.

[2] I. M. Kolthoff and J. F. Coetzee, "Electrochemical Reduction of Americium and Some Rare Earth Elements in Acetonitril," Journal of American Chemical Society, Vol. 79, No. 20, 1957, pp. 1852-1859.

[3] R. S. Pandey, and S. Dugar, "Thermodynamics Studies of Zinc Ethylenediamine Complexes in Aqueous-NonAqueous Media by Polarography," Asian Journal of Experimental Sciences, Vol. 15, No. 1-2, 2001, pp. 49-62.

[4] D.K. Sharma, S. Kumar, C. Chauhan and A. Gupta, "A Pulse Polarographic Method for the Analysis of Zinc Dithiocarbamates," Indian Journal of Chemistry, Vol. 46, No. 7, 2007, pp. 1121-1124.

[5] E.-S. M. Mabrouk, H. M. Killa et al., "Polarographic and Cyclic Voltammetric Behaviour of Some Azo Compounds Derived from Sulfonamide in DMF-Aqueous Solutions," Collection of Czechoslovak Chemical Communications, Vol. 57, No. 2, 1992, pp. 268-275.

[6] J. Rzeszotarska, P. Ranachowski and M. K. Kalinowski, "Donor Numbers for Binary Mixtures of Dimethyl Sulfoxide with Dipolar Aprotic Solvents," Collection of Czechoslovak Chemical Communications, Vol. 59, No. 10, 1994, pp. 2201-2208.

[7] N. G. Tsierkezos, J. Roithova, D. Schröder, I. E. Molinou and H. Schwarz, "Solvation of Copper(II) Sulfate in Binary Water/N, N-Dimethylformamide Mixtures: From the Solution to the Gas Phase," The Journal of Physical Chemistry B, Vol. 10, No. 112, 2008, pp. 4365-4371.

[8] G. H. Rounaghi, Z. Eshagi and E. Ghiamati, "Study of the Complex Formation Between 18C6 Crown Ether and $\mathrm{Tl}^{+}, \mathrm{Pb}^{2+}$ and $\mathrm{Cd}^{2+}$ in Binary Non-aqueous Solvents Using Differential Pulse Polarography," Talanta., Vol. 43, No. 7, 1996, pp. 1043-1048.
[9] G. H. Rounaghi, G. N. Gerey and M.S. Kazemi, "A Conductometric Study of Complexation Reactions between Dibenzo-18-Crown-6 (DB18C6) with $\mathrm{Cu}^{2+}, \mathrm{Zn}^{2+}, \mathrm{Tl}^{+}$and $\mathrm{Cd}^{2+}$ Metal Cations in Dimethylsulfoxide-Ethylacetate Binary Mixtures," Journal of Inclusion Phenomena and Macrocyclic Chemistry, Vol. 56, No. 1, 2006, pp. 167172.

[10] A. Nezhadali, P. Langara and H. A. Hosseini, "Study of Complex Formation Between Iodoquinol (IQ) and $\mathrm{Co}^{2+}$, $\mathrm{Mn}^{2+}, \mathrm{Pb}^{2+}, \mathrm{Cd}^{2+}$ and $\mathrm{Zn}^{2+}$ Cations in Binary Aqueous/Non-Aqueous Solvent Using Spectrophotometry," Electronic Journal of Chemistry, Vol. 4, No. 4, 2007, pp. 581-586.

[11] A. Nezhadali, P. Langara and H. A. Hosseini, "Study of Complex Formation Between 5,7-Diiodo-8-HydroxyQuinoline and $\mathrm{Zn}^{2+}, \mathrm{Cd}^{2+}, \mathrm{Pb}^{2+}$ and $\mathrm{Tl}^{+}$Cations in Binary Non-Aqueous Solvents Using Squre Wave Polarography Technique (SWP)," Journal of Chinese Chemical Society, Vol. 55, 2008, pp. 271-275.

[12] H. A. Azab, "Polarographic Study of Composition and Stability Constants of $\mathrm{Pb}$ (II) N-(2-Acetamido) Imino Diacetate Complexes," Journal of Monatshefte für Chemie/Chemical Monthly, Vol. 123, No. 12, 2004, pp.11071115.

[13] A. Nezhadali, G. H. Rounaghi and M. Chamsaz, "Stoichimetry and Stability of Complexes Formed between 18Crown-6 as well as Dibenzo-18-Crown-6 Ligands and a Few Metal Ions in Some Non-Aqueous Binary Systems Using Square Wave Polarography," Bulletin of Korean Chemical Society, Vol. 21, No. 7, 2000, pp. 685-689.

[14] T. Çaykara, R. İnam, Z. Öztürk and O. Güven, "Determination of the Omplex Formation Constants for Some Water-soluble Polymers with Trivalent Metal ions by Differential Pulse Polarography," Polymer Science, Vol. 282, No. 7, 2004, pp. 1282-1285.

[15] G. H. Rounaghi, M. Chamsaz and and A. Nezhadali, "A Polarographic Study $\mathrm{Tl}^{+}, \mathrm{Pb}^{2+}$ and $\mathrm{Cd}^{2+}$ Complexes with Azo-18-Crown-6 and Dibenzopyridino-18-Crown-6 in Some Binary Mixed Non-Aqueous Solvents," Journal of Inclusion Phenomena and Macrocyclic Chemistry, Vol. 38, No. 1, 2000, pp. 153-161.

[16] B. S. Bairwa, M. Goyal, I. K. Sharma, S. Varshney and P. S. Verma, "Electrochemical Behaviour of Ni(II) Lamino Acid in Aqueous Dimethylformamide, NmethylforMamide and Formamide Media at Dme," Indian Journal of Chemistry, Vol. 46, No. 10, 2007, pp. 778-782.

[17] J. N. Gaur and N. K. Goswami, "Kinetics of the Reduction of $\mathrm{Mn}^{2+}$ at the Dropping Mercury Electrode in NonAqueous Media," Electrochimica Acta, Vol. 12, No. 11, 1967, pp. 1489-1493. 